Pakistan Journal of Social Sciences 7 (2): 129-136, 2010

ISSN: $1683-8831$

(C) Medwell Journals, 2010

\title{
Prevalence and Predictors of Anti Social Behaviours: A Cross Sectional Survey of Adolescents in Secondary Schools in Owerri Municipal, South East Nigeria
}

\author{
${ }^{1}$ Benjamin O. Nwankwo, ${ }^{1}$ Eunice U. Nwoke, ${ }^{1}$ Uche M. Chukwuocha, \\ ${ }^{2}$ Adolphus O. Obanny, ${ }^{3}$ Kachy S. Nwoga, ${ }^{4}$ Uchechukwu O. Iwuagwu and ${ }^{5}$ Chinwe Okereke \\ ${ }^{1}$ Department of Public Health Technology, Federal University of Technology, Owerri, Imo State, Nigeria \\ ${ }^{2}$ Imo State College of Health Sciences and Technology, Amaigbo, Nigeria \\ ${ }^{3}$ Central Medicare, \#43 Okigwe Road, Owerri, Imo State, Nigeria \\ ${ }^{4}$ Department of Registry, Federal University of Technology, Owerri, Imo State, Nigeria \\ ${ }^{5}$ Department of Educational Psychology, Imo State University, Owerri, Nigeria
}

\begin{abstract}
Behaviour is considered abnormal or antisocial if it does not conform to what society expects. These anti social behaviours according to findings are more common among the adolescents, hence the rationale for this study among adolescents in Owerri Municipal. The study lasted four months (September-December, 2009). The sample for this study consists of 500 randomly selected adolescents drawn from five randomly selected secondary schools in Owerri municipal. The major instrument used for primary data collection was a self constructed but validated questionnaire that sought information on respondents bio data, prevalence of anti social behaviour, causes as well as association between the most prevalent forms of anti social behaviour and respondents' bio data. The study concluded that much antisocial behaviour exists among adolescents in secondary schools in Owerri Municipal with cultism being the most prevalent. Peer influence was found to be the major factor responsible for the prevalence of these antisocial behaviours among the sampled adolescents. These anti social behaviours were found to be significantly associated with the respondents gender, religion, parents economic status and parenting style $(\mathrm{p}<0.05)$. It is recommended among others that in line with the spirit of the laudable objectives of family planning, parents should endeavour to bear children they can comfortably cater for which includes appropriately providing for their needs economically, morally, psychologically and socially.
\end{abstract}

Key words: Antisocial, behaviour, adolescents, Owerri Municipal, South East, Nigeria

\section{INTRODUCTION}

Behaviour is considered abnormal or antisocial if it is uncommon, different from the norm and does not conform to what society expects. This idea is also closely related to the statistical approach to definite abnormality which rest on the idea that differences in human behaviour tends to fall into a normal distribution curve (Nwankwo, 2006a). A particular behaviour is not acceptable or is antisocial if any of these three criteria are seen; the behaviour does not allow a person to function effectively with others as member of society, if the behaviour does not permit the person to meet his or her own needs and the behaviour has a negative effect in the well being of others (Roberts, 1981).

However young people are segregated from adult society and such segregation serves as an important contribution to antisocial behaviour by teenagers. Period of adolescence is the most crucial period in the life of human beings and is the stage where life reaches its peak (Nwankwo, 2006a). The adolescent is eager to learn new experiences, to find new relationships, to examine resources of inner strength and fathom the strength of inner ability However, antisocial personality disorder is one the most significant types of personality disorder (Hayes and Minardi, 2002a, b). People with the social problems make life miserable for those around them. They typically display no regard for the moral of ethical rules of the society or the rights of others, manipulating people and situation for their own benefits. They display little guilt when they have injured someone else and even understand that they may have caused a person some harm but feel no remorse (Roberts, 1981). Antisocial people are unable to stand frustration and they are impulsive. These traits lead to stealing, lying and cheating. They often have unusually good social skill and

Corresponding Author: Benjamin Osondu Nwankwo, Department of Public Health Technology,

Federal University of Technology, Owerri, P.M.B. 1526, Imo State, Nigeria 
their charm and appearance allow them to convince others to comply with their wishes (Loeber, 1990; Bell, 1986). These behaviours however, are more common among juvenile and also peculiar to adolescents (Blumstein et al., 1988; Miller et al., 1982; Loeber, 1990). According to Dryfoos (1990), statistics shows that between 35 and 40\% of all boys growing up in an urbanized area will be arrested before their 18th birthday. There are evidences from previous studies of probability of anti social behaviours being interrelated, retained or progressive (Kandel et al., 1986; Kandel, 1982; Brennan et al., 1981; Loeber, 1990).

Some of these anti social behaviours are traits which run in families (Ary et al., 1999a, b). Family management practices such as marital breakdown, different caretakers, harsh and inconsistent discipline or multiple mothering in early childhood are important factors in developing aggressive and anti social behaviour in adolescents later in life (Ary et al., 1999 a, b; Marttunen et al., 2007; Loeber and Stouthamer-Loeber, 1986; MacDonald, 1985). Antisocial behaviour is assumed to have resorted from faulty or inappropriate learning behaviour which consists of combination of learned association combined into ever larger chunks (Hamburg, 1974). According to Bandura (1997, 1986), Nwankwo (2006a, b), Loeber (1990) and Loeber and Stouthamer-Loeber (1986), people behave aggressively because of humiliating behaviour which they have learned vicariously from watching others especially their peers. Behaviour is motivated by mental processes which individuals are often not aware. Behaviour is also part of a coherent whole personality which reflects both to current reflection and past experiences (Loeber, 1982; Cimbora and McIntosh, 2003).

The rates of increase in antisocial behaviour in the society is alarming (Loeber, 1990; Jamieson and Flanagan, 1987) and is evidenced in the number of people who die of suicide, rape, murder and disease like arteriosclerosis and sexually transmitted diseases like AIDS. However, exposure to incidence of violence and law breaking of all kinds are common places. Alcoholism, drug abuse, smoking, suicide (Loeber, 1990; Bell, 1986) and others such as rape, cultism, prostitution, kidnapping, ritual are all antisocial behaviours which are traceable mostly from families with poor economic background, children from unstable family background (Ary et al., 1999a, b) or from children who have experienced major negative life events such as death of parents, children with frequent hassles of everyday life and frustration (Nwankwo, 2006a). Anti social behaviours are not restricted to males alone but has been found to be prevalent among adolescent girls also (Robins, 1986; Rutter and Giller, 1983). The academic institutions are not spared as they have been implicated as breeding grounds for most anti social behaviours or social vices. Undoubtedly, one of such social vices among other cancerous problems confronting Nigeria educational institutions today is cultism as there is hardly any academic session without reported cases of cultism in most Nigerian institutions as according to Ogidefa (2008), there is hardly any single Nigerian institution of higher learning that has not experienced this menace of cultism. The youths and students and even the aged are continuously exposed to numerous risk of life styles due to poverty, group or peer influences (Zajonc and McIntosh, 1992). These unhealthy life styles lead to almost two third of deaths cases and injuries in the society (Marttunen et al., 2007). Behaviours like alcoholism, smoking, drug abuse, prostitution and rape exposes people to diseases and disorders like cardiovascular collapse, cirrhosis of the liver, insomnia, loss of appetite, syphilis, gonorrhoea, candidiasis and even death. It can also damage the body parts like tearing and bruises or lead to sterility, infertility and psychiatric cases. This is evident in most psychiatric homes (Nwankwo, 2006a). However, antisocial behaviours have been consistently reported to have come from environments characterised by parental rejection, permissiveness, aggression, lack of parental care, a low level of parental expectation, family discord, inconsistency in treatment and use of physical and painful punishment (Bandura, 1977; Ary et al., 1999a, b; MacDonald, 1985).

Factors influencing these anti social behaviours range from unfavourable family relationship (Ary et al., $1999 a$, b) biological and physical changes, social expectation, social acceptance, fashion, inferiority feeling, pride and rebellion against parents, authorities and elders, struggle to achieve independence from family, career choice, struggling to achieve economic independence, substance abuse (Nwankwo, 2006a).

To this end the researchers were motivated to ascertain the prevalence and predictors of antisocial behaviours among adolescents in Owerri Municipal area of Imo State. The study sought to address the following objectives and questions:

- To determine the existence of antisocial behaviours among adolescence in this area

- To ascertain the most prevalent or common form of antisocial behaviour among adolescents in this area

- To determine the factors responsible for the prevalence of antisocial behaviours among adolescents in Owerri municipal

- To determine whether the prevalent anti social behaviours among adolescents in Owerri municipal is based on some selected socio demographic variables such as religious affiliation, adolescents parents economic status, gender or adolescents family backgrounds 
The result of this study is intended to enable individuals, policy makers, health educators, health care providers, curriculum planners and the government to make adequate plan on how to ensure that the high level antisocial behaviours among adolescents is drastically reduced. On the side of the individuals, it will go a long way in ensuring or implanting an acceptable lifestyle and perception towards ones health. Again it will enable policy makers to realise the need for enacting and enforcing appropriate policies that will be of help and bring about the welfare of the adolescents. It will also help the adolescents realize how to improve on behaviour that are positive towards their wellbeing. Socially, it is intended to encourage acceptable social standards and encourage a sanitized environment free from violence, corruption and other social problems.

Theoretical basis to understanding antisocial behaviour Theory of Reasoned Action (TRA): This theory looks at behaviour intentions rather than attitudes as the main predictors of behaviours (Ajzen and Fishbein, 1980, 2005). The researchers assumed that individuals are usually quite rational and make systematic use of information available to them. People consider the implications of their action before they decide to engage or not engage in a given behaviour (Ajzen and Fishbein, 1980, 2005). According to the theory, the most important determinant of a person's behaviour is a combination of attitude toward performing the behaviour and subjective norm. If a person perceives that the outcome from performing behaviour is positive, she or he will have a positive attitude towards performing that behaviour.

The opposite can also be stated if the behaviour is thought to be negative. Subjective norm is seen as a combination of perceived expectations from relevant individuals or groups along with intentions to comply with these expectations.

In other words, the person's perception that most people who are important to him or her think he should or should not perform the behaviour in question (Ajzen and Fishbein, 2005). TRA works most successfully when applied to behaviours that are under a person's volition or control. If behaviours are not fully under control, even though a person may be highly motivated by his or her own attitudes and subjective norm, he or she may not actually perform the behaviour due to intervening environmental conditions.

Theory of Planned Behaviour (TPB): A counter argument against the high relationship between behavioural intention and actual behaviour has also been proposed as results of some studies do not show that behavioural intention always leads to actual behaviour because of circumstantial limitations. Namely, since behavioural intention cannot be the exclusive determinant of behaviour where an individual's control over the behaviour is incomplete, Ajzen (1985) introduced the TPB by adding a new component, perceived behavioural control. By this, he extended the TRA to cover volitional behaviours for predicting behavioural intention and actual behaviour (Ajzen, 1985, 1991). As an extension of TRA, this is one of the most predictive persuasions theories which looks at behavioural intentions as being the immediate antecedents to behaviour. It is believed that the stronger a person's intention to perform a particular behaviour, the more successful they are expected to be. The TPB adds the concept of perceived behavioural control which is conceptually related to self efficacy. Intentions are functions of salient beliefs and or information about the likelihood that performing a particular behaviour will lead to a specific outcome. However, intention can change overtime because the longer the time between intention and behaviour, the greater the likelihood that unforeseen events will produce change in intentions. Perceived behaviour control can influence behaviour directly or indirectly through behavioural intention. People are not likely to form a strong intention to perform a particular behaviour, if they believe that they do not have any resources or opportunities to do so even if they hold positive attitudes towards the behaviour and believe that important others would approve of the behaviours.

Applicability of the theories: In particular, recently, several studies found that the TPB would better help to predict health-related behavioural intention than the TRA (Ajzen, 1985) given that TPB has improved the predictability of intention in various health-related fields such as condom use or in this case anti social behaviour. TPB model is thus a very powerful and predictive model for explaining human behaviour. The applicability of these theories to understanding anti social behaviours among adolescents becomes more apt when we consider the influences of parental background and upbringing or peer pressure in determining later anti social behaviours among adolescents. Family management practices such as marital breakdown, different caretakers, harsh and inconsistent discipline or multiple mothering in early childhood are important factors in developing aggressive and anti social behaviour in adolescents later in life (Ary et al., 1999a, b; Marttunen et al., 2007; Loeber and Stouthamer-Loeber, 1986; MacDonald, 1985). Concerning peers, people behave aggressively because of humiliating behaviour which they have learned vicariously from watching others especially their peers (Loeber, 1990; Loeber and Stouthamer-Loeber, 1986). 


\section{MATERIALS AND METHODS}

A survey research design, which is an attempt to collect data from a population with respect to one or more variables was used in this study. The population of the study comprises of an estimated 10,000 adolescents in the 10 secondary schools in Owerri Municipal as at the time of study. The sample for this study consists of 500 randomly selected students drawn from five randomly selected secondary schools in Owerri municipal. This figure tallies with the sample estimate of $5 \%$ when the sample is in few thousands (Ejifugha, 2004). Each selected school was proportionally allocated an equal size of 100 each. The major instrument used for primary data collation was a self constructed but validated questionnaire. The questionnaire was divided into two sections. Section A contained information on personal data of students, while section $\mathrm{B}$ sought information on the major objectives of the study. The validated instrument was pilot tested in another secondary school not used in this study and it was re administered after 1 week. A correlation coefficient result of $r=0.72$ was achieved indicating usability of instrument. Instrument administration which lasted one month (November, 2009) was done on a face to face basis. Data analysis using only 454 validly returned copies of questionnaire (indicating a $91.8 \%$ return rate) was done with a Software Statistical Package (SPSS).

\section{RESULTS AND DISCUSSION}

Respondents bio data: Out of the 454 respondents, majority $299(65.9 \%)$ were males, while $155(34.1 \%)$ were females. Majority $295(65 \%)$ of the respondents were aged between $16-18$ years, $129(28.4 \%)$ were within $13-15$ years, while $30(60.6 \%)$ were aged 18 years above. Many of the respondents, 442 (97.4\%) were Christians, $10(2.2 \%)$ were Muslims, while two $(0.4 \%)$ were adherents of a traditional religion. Majority $262(67.7 \%)$ of the respondents parents were farmers, traders or businessmen, many 177 (38.9\%) of the respondents parents were civil/public servants, while $15(3.3 \%)$ of the respondents parents were either retried or aged. On respondents parenting style, majority 344 (75\%) of respondents came from democratic family setting, 71 $(15.6 \%)$ said they came from an autocratic family settings, while $39.0(8.6 \%)$ said their parents didn't care much (lesser affair).

Prevalent anti social behaviour: Majority 312 (68.7\%) of the students greed that cultism is the major anti social behaviour prevalent among these adolescents and youths in the society today. This is followed by responses on smoking $61(13.4 \%)$, truancy $56(12.3 \%)$, alcoholism 13
$(3.0 \%)$ and drug abuse $12(2.6 \%)$ (Table 1$)$. Majority 171 $(37.7 \%)$ of students were of the view that peer group influence predisposes adolescents and youths to antisocial behaviour, many $140(30.8 \%)$ said it is poor parenting styles, some $58(12.8 \%)$ cited religion/moral decadence, few others $(12.6 \%)$ maintained that the cause is traceable to family economic status, while $28(6.2 \%)$ said media influence causes antisocial behaviour (Table 2).

Association between selected socio demographic variables and prevalent anti social behaviour: Three most prevalent anti social behaviours (cultism, smoking and truancy) were selected (Table 1) and matched in form of hypothesis against some selected variables such as respondents' gender, respondents' parents religion, respondents' economic status and respondents' parenting style in other to ascertain any significant association at an alpha level $(\alpha=0.05)$. A significant association was found to exist between the dependent (anti social behaviour) and independent variables (selected respondents' socio demographic variables) $(\mathrm{p}<0.05$, Table 3$)$.

The present study has demonstrated the existence of anti social behaviours such as cultism, truancy, alcoholism, smoking and drug abuse among adolescents in secondary schools in Owerri Municipal. Though their existence was quantitatively but differently assessed, Roberts (1981) had earlier revealed in his study that the prevalence of anti social behaviours among adolescents in secondary schools is a common occurrence these days as there are many thousand cases every year. Adolescents whose parents are poor also and always associate with bad peers whereas the reverse is the case for adolescents whose parents are rich. The later grow up without being a deviant or being involved in any antisocial behaviour (Roberts, 1981). Cultism was found to be the most prevalent form of anti social

Table 1: Frequency distribution of anti social behaviour existing in sampled schools

\begin{tabular}{lrc}
\hline Anti social behaviour & \multicolumn{1}{c}{ F } & Percentage \\
\hline Truancy & 56 & 12.3 \\
Cultism & 312 & 68.7 \\
Drug abuse & 12 & 2.6 \\
Smoking & 61 & 13.4 \\
Alcoholism & 13 & 3.0 \\
Total & 454 & 100.0 \\
\hline
\end{tabular}

Table 2: Major causes of anti social behaviour existing in sampled schools Major causes

Poor parenting style

Religions/moral decadence

Family economic status

Peer influence

Media influence

$\underline{\text { Total }}$ Percentage 30.8 12.8 12.6 37.7

6.2 100.0 
Pak.J.Soc. Sci., 7 (2): 129-136, 2010

Table 3: Association between selected variables and prevalent anti social behaviour Variables

\begin{tabular}{|c|c|c|c|c|c|c|c|c|c|c|c|c|}
\hline \multirow{2}{*}{$\begin{array}{l}\text { Prevalent anti } \\
\text { social behaviour }\end{array}$} & \\
\hline & Christianity & Moslem & Traditional & Total & $\chi^{2}$ & p-value & Farmer/Trader & Civil servant & Retired/Aged & Total & $\chi^{2}$ & $p$-value \\
\hline \multicolumn{7}{|c|}{ (a) Respondents' parents religion } & \multicolumn{6}{|c|}{ (b) Respondents' parents economic status } \\
\hline Cultism & 186 & 6 & 0 & 194 & - & & 127 & 59 & 8 & 194 & - & \\
\hline Smoking & 159 & 3 & 2 & 164 & - & & 65 & 94 & 3 & 162 & - & \\
\hline Truancy & 97 & 1 & 0 & 96 & - & & 70 & 24 & 4 & 98 & - & \\
\hline \multirow[t]{2}{*}{ Total } & 442 & 10 & 2 & 454 & 39.8 & $<0.05$ & 262 & 177 & 15 & 454 & 35.812 & $<0.05$ \\
\hline & Male & Female & Total & $\chi^{2}$ & & $p$-value & Autocratic & Democratic & Laissez Faire & Total & $\chi^{2}$ & $\mathrm{p}$-value \\
\hline \multicolumn{4}{|c|}{ (c) Respondents gender } & \multicolumn{9}{|c|}{ (d) Respondents' parents parenting style } \\
\hline Cultism & 139 & 55 & 194 & - & & & 22 & 159 & 15 & 194 & - & \\
\hline Smoking & 62 & 100 & 167 & - & & & 22 & 157 & 15 & 162 & - & \\
\hline Truancy & 98 & 0 & 96 & - & & & 25 & 59 & 14 & 98 & - & \\
\hline Total & 299 & 155 & 454 & 10.900 & & $<0.05$ & 71 & 344 & 39 & 454 & 15.57 & $<0.05$ \\
\hline
\end{tabular}

behaviour found among the sampled respondents (Table 1). Cultism can be defined (Ogidefa, 2008), as a ritual practice by a group people whose membership, admission, policy and initiation formalities as well as their mode of operations are done in secret and kept secret with their activities having negative effects on both members and non-members alike. The result in Table 1 is expected as many students in the locality as well as other similar localities these days engage in cultism for so many reasons which include among others to pass exams to be feared and respected, to assume some level of protection. Again, other reasons for student's involvement in cultism according to Ogidefa (2008), range from parent's involvement in similar activities, Children from broken homes. A home that is characterized by child abuse, intolerance, violence, insecurity and hostility, the societal mad ambition for wealth and power, children who have emotional sickness who tend to be frustrated and fed up with life, peer group's influence, support given by staff of educational institutions who are members of secret cults, government's lukewarm attitude in enforcing strict penalties for offenders, inadequate religious and moral instructions/education, administrative style of institutional administrators who don't get other stake holders involved in decision making, students unlimited access to uncensored mass media, inadequate welfare programmes for students among others.

Next to cultism in that order is smoking. The result is anticipated in that it is easier for adolescents to retire to a corner of the road or bush to smoke than it is for them to drink alcohol (Nwankwo, 2006b). While at school, smoking is considered by boys as sign of manhood or status. This transient flirtation with smoking may later become a permanent habit, unless quickly checked (Christie-Smith, 1999; Hines et al., 1998). Students and adolescents constitute a greater proportion of smokers as research has shown that habits generally begin in the early teens (Doll, 1990) and peer pressure continues to be a major influencing factor (Nwankwo et al., 2008). Teenagers also often start smoking in imitation of the older people who smoke. Elegbeleye (1997) and Nwankwo et al. (2008) asserted that peer smoking is clearly related to peer influence which is extremely important in the development of smoking habit, particularly during the teenage and college years. This may continue if it is an accepted and admired habit within their social group. The result on smoking attribute as a major anti social behaviour corresponds with Edwin (1991) assertion that young people often try their first cigarette at the urging of their friends and they may continue to smoke if it is an accepted and admired habit within their social group. These assertions confirm result shown in Table 2 concerning peer influence and smoking behaviour. Data from the 1989 Teenage Health and Lifestyles survey of secondary school children in England reveal that young people are more likely to be smokers if other people at home smoke. Siblings seem to be more influential than parents in this respect. When both parents smoke, children are more than twice more likely to be regular smokers than if neither parent smokes (Doll, 1990). Adolescents are well known for their irresistible ability to explore, experiment with new things, ideas or materials including chemical substances. In a study on antecedents of smoking behavior among male adolescent students in south east region of Nigeria, Nwankwo et al. (2008) found out that of a total of 2010 adolescents who were enrolled into the study, a greater number $1680(83.6 \%)$ were either currently smoking or had ever smoked indicating a high prevalence of cigarette smoking among this group. Studies (Rigotti et al., 2000) conducted in 1999 among US college students $(n=14$, 138) concluded that $53.4 \%$ of all college students reported ever having smoked a cigarette. The US Department of Health and Human Services (Centers for Disease Control, 1997) indicated that majority of the adolescent's transit to college showing progression into adulthood and the freedom to make self-initiated choices, including the decision whether to smoke. On intention and reason, the development of smoking may be a gradual process. Buying cigarettes even for another person is an early part 
of smoking behavior. Inhaling the smoke and increasing consumption gradually follow and eventually people begin to smoke more openly in front of others (Goddard, 1990). Studies concerning the transition from experimental to regular smokers have identified predicators such as modeling and approval by peer group an independently risk taking personality, exaggerated prevalence estimates and attitudes and intentions favourable to smoking (Chalton and Blair, 1989).

The study also identified truancy as another major anti social behaviour exhibited by the adolescents. Truancy has been associated with and often regarded as one of the effects, off shoots and expressions of negative emotions such as anger, envy, greed, fear, hatred, shame, blame, regret, resentment, hostility, worry, jealousy etc which interfere and hamper ones mental, social and emotional wellbeing (Nwankwo, 2006a). One of the major problems observed in the schools (Nwankwo, 2006a) is the treatment of all children as if their emotional and psychological needs were identical. The result is many children's needs are unsatisfied. They then become frustrated and may act out their frustration in various ways such as truancy, which are typically seen as misbehaviour.

However, the inability of most adolescents to resolve emotional or psychological problems early in life in the course of fulfilling their normal development tasks, may lead to negative consequences later in life. Developmental tasks are problems or tasks which arise in certain period of individual development that he or she has to accomplish, resolve, master or contain if he is to become a successful, normal and well-adjusted person in the society. Accordingly successful achievement, satisfaction, resolution of these tasks will lead to happy satisfying period of life, while failure leads to unhappiness, disapproval, non recognition, frustration, stress, substance abuse, crime, truancy, delinquency and many bad life styles and behaviours (Nwankwo, 2006a).

Results from Table 2 indicate that poor parenting style is a major cause of antisocial behaviour among adolescents. Parenting style is a serious factor affecting adolescent's future lifestyle. When a child is modelled in a right way and at the right time, there are strong assurances that he or she may grow up to be a good citizen. The Biblical injunction found in Proverbs 22 verse 6 train up a child in the way he should go and when he is grown, will not depart from it, tends to completely agree with the above finding. Family management practices such as marital breakdown, different caretakers, harsh and inconsistent discipline or multiple mothering in early childhood are important factors in developing aggressive and anti social behaviour in adolescents later in life (Ary et al., 1999a, b; Marttunen et al., 2007; Loeber and Stouthamer-Loeber, 1986; MacDonald, 1985).

In this study, though adolescents from a Christian background were found more likely that their other religion's counterparts to have engaged in the three most prevalent forms of anti social behaviours, it needs be noted however that the study was conducted in a predominantly Christian community even when anti social behaviours cuts across religious or ethnic frontiers. The study had also documented a male predominance of the anti social behaviours. To this end, Nwankwo et al. (2008) had earlier opined that males engage more in antisocial behaviour such as smoking somewhat earlier and heavier than their female counterparts. Males tend to try everything in the world with the view of finding what it is and by so doing some remain permanent deviants. This does not in the views of Robins (1986) and Rutter and Giller (1983), exclude adolescent girls who have also been found to be partakers of the same negative behaviours in almost equal magnitude.

Family economic status was also implicated in this study as another factor of influence in adolescent anti social behaviour (Table 2). To this end, Nwankwo (2004) had demonstrated that poverty which is deeply rooted in Africa has the capability if it is acute to trap succeeding generations. This trapping may translate into parents not being able to meet up with their obligations to their children, thereby pushing their children to conduct themselves in manners that society considers abnormal or anti social.

Based on these findings, the study showed that much antisocial behaviour exists among adolescents in schools in Owerri Municipal with cultism being the most prevalent. Peer influence was found to be the major factor responsible for the prevalence of antisocial behaviour among adolescents in Owerri Municipal. These anti social behaviours were found to be significantly associated with the respondents gender, religion, parents economic status and parenting style $(\mathrm{p}<0.05$, Table 3$)$.

\section{CONCLUSION}

Cultism and other anti-social or deviant behaviour usually contravenes the norms or social rules of an institution that is meant to provide education for the individual or student (Ogidefa, 2008). Specifically, it is speculated that a number of primary and secondary school students are also members of secrets cults. It is in the face of these emerging challenges and other reasons that the federal government deemed it of great importance to introduce guidance and counseling to all levels of the nation's education (Ogidefa, 2008). Guidance and 
counseling like education is concerned with the all-round development of the students. The broad defined objectives of counseling is to help the client/student achieve self-understanding; to help individual towards overcoming obstacles to their personal growth and development wherever these may be encountered and towards achieving optimum development of their personal resources. By training, the counsellor is equipped to devise several preventive and constructive programmes for dealing with maladaptive or deviant behaviours and for inculcating lasting values (Ogidefa, 2008). Thus the resultant effort is the individual having a balanced personality.

\section{RECOMMENDATIONS}

Parents should put more effort to ensure that their children are adequately provided for and morally groomed. This call to question the issue and justification for family planning which among other objectives seeks to ensure that parents only give birth to children they can comfortably cater for. Intensive seminars and workshops should be regularly organised for these formative adolescents to keep driving home to them the dangers of anti social behaviours. Proper guidance and counselling should always be given to them at home and in school by those qualified and recruited to such a high responsibility. However, strict penalties should be meted to offenders to act as a deterrent to other adolescents who may be nurturing the intention to engage in such anti social behaviours.

The researchers suggest the application of caution in generalizing the findings of this study to other larger population and therefore recommend highly the replication of this baseline descriptive study since according to authorities such as Loeber et al. (1989), this study is based on small sample size. We also recommend a longitudinal prospective or retrospective cohort study to ascertain a causal relationship between family dispositions and later development of anti social behaviour among adolescents in the setting.

\section{REFERENCES}

Ajzen, I. and M. Fishbein, 1980. Understanding Attitudes and Predicting Social Behavior. Prentice-Hall, Englewood Cliffs, NJ

Ajzen, I. and M. Fishbein, 2005. The Influence of Attitudes on Behavior. In: The Handbook of Attitudes, Albarracin, D., BT. Johnson and M.P. Zanna (Eds.). Lawrence Erlbaum Associates, New Jersey.
Ajzen, I., 1985. From Intentions to Actions: A Theory of Planned Behavior in Springer Series. In: Social Psychology, Kuhl, J. and J. Beckmann (Eds.). Springer, Berlin, pp: 11-39.

Ajzen, I., 1991. The theory of planned behavior. Org. Behav. Hum. Decision Processes, 50: 179-211.

Ary, D.V., T.E. Duncan, A. Bigian, C.W. Metzler, J.W. Noell and K. Smolkowsky, 1999a. Development of adolescent problem behaviour. J. Abnormal Child Psychol., 27: 141-150.

Ary, D.V., T.E. Duncan, S.C. Duncan and H. Hops, 1999 b. Adolescent problem behaviour: The influence of parents and peers. Behav. Res. Therapy, 37: 217-230.

Bandura, A., 1977. Self efficacy: Towards a unifying theory of behaviour change. Psychol. Rev., 84: 191-215.

Bandura, A., 1986. Social Foundations of Thought and Action: A Social Cognitive Theory. Prentice Hall, Englewood Cliffs, New Jersey.

Bandura, A., 1997. Self-Efficacy: The Exercise of Control. Freeman Press, New York, ISBN: 9780716726265 , pp: 604 .

Bell, R.Q., 1986. Age-Specific Manifestations in Changing Psychosocial Risks. In: Risk in Intellectual and Psychosocial Development, Faran, D.C. and J.D. McKinney (Eds.). Academic Press, Orlando, pp: 169-185.

Blumstein, A., J. Cohen and D.P. Farrington, 1988. Criminal career research: Its values for criminology. Criminology, 26: 1-36.

Brennan, T., D.S. Elliott and B.A. Knowles, 1981. Patterns of multiple drug use: A descriptive analysis of static types and change patterns, 1976-1978. A Report of the National Youth Survey, Behaviour Research Institute.

Centers for Disease Control, 1997. Youth risk behavior surveillance. National College Health Risk Behavior Survey. US Department of Health and Human Services. MMWR, 46: SS-6.

Chalton, A. and V. Blair, 1989. Predicting the onset of smoking in boys and girls. Soc. Sei. Med., 49: 813-818.

Christie-Smith, D., 1999. Smoking cessation programs need to target colleges. Am. J. Health Syst. Pharm., 56: $416-416$.

Cimbora, D.M. and D.N. McIntosh, 2003. Emotional responses to antisocial acts in males with conduct disorder: A link to affective morality. J. Clin. Child Adolescent Psychol., 32: 296-301.

Doll, R., 1990. Cigarette smoking among high school students. Am. J. Publ. Health, 19: 1499-1511. 
Dryfoos, J.G., 1990. Adolescents at Risk: Prevalence and Prevention. 2nd Edn., Oxford University Press, New York, ISBN-13: 9780195179620 , pp: 61-77.

Edwin, J., 1991. Healthful Living. The CY Mosby Co., London.

Ejifugha, A.U., 2004. Fundamentals of Research in Health Education. Baloz Publishers, Owerri, pp: 201.

Elegbeleye, C.O., 1997. Incidence and variables contributing to onset of cigarette smoking among secondary school children and medical students in Lagos Nigeria. Br. J. Preven. Soc. Med., 67: 232-237.

Goddard, E., 1990. Why Children Start Smoking?. HMSO, London.

Hamburg, B., 1974. Early Adolescence: A Specific and Stressful Stage of the Life Cycle. In: Coping and Adaptation, Goehol, G., D.A. Hamburg and J.E. Adams (Eds.). Basic Books, New York, pp: 101-125.

Hayes, N. and H. Minardi, 2002a. Psychology and Ageing. In: Ageing-Issues for Physical, Psychological and Social Health, Woodrow, P. (Ed.). Chap. 7, Whurr Publishers Ltd., London, pp: 93-114.

Hayes, N. and H. Minardi, 2002b. Abnormal Psychology in Old Age. In: Ageing-Issues for Physical, Psychological and Social Health, Woodrow, P. (Ed.). Chap. 8, Whurr Publishers Ltd., London, pp: 115-138.

Hines, O., A.C. Fretz and N.L. Nollen, 1998. Regular and ocational smoking by college: Personality attributions of smokers and non smokers. Psychol. Rep., 83: 1299-1306.

Jamieson, V.M. and T.J. Flanagan, 1987. Source Book for Criminal Justice Statistics-1986. US Department of Justice, Woshington, DC.

Kandel, D.B., 1982. Epidemiological and psychological perspectives on adolescent drug use. J. Child Psychiatry, 21: 328-347.

Kandel, D.B., O. Simcha-Faganand and M. Davies, 1986. Risk factors for delinquency and illicit drug use from adolescence to young adulthood. J. Drug Issues, 16: 67-90.

Loeber, R. and M. Stouthamer-Loeber, 1986. Family Factors as Correlates and Predictors of Juvenile Conduct Problems and Delinquency. In: Crime and justice: An Annual Review of Research, Morris, N. and M. Tonry (Eds.). Vol. 7, University of Chicago Press, Chicago, pp: 29-149.
Loeber, R., 1982. The stability of antisocial and delinquent child behaviour: A review. Child Dev., 53: 1431-1446.

Loeber, R., 1990. Development and risk factors of juvenile antisocial behaviour and delinquency. Clin. Psychol. Rev., 10: 1-41.

Loeber, R., R.E. Tremblay, C. Gagnon and P. Charliebois, 1989. Continuity and desistance in early fighting in school. Dev. Psychopathol., 1: 39-50.

MacDonald, K., 1985. Early experience, relative plasticity and social development. Dev. Rev., 5: 91-121.

Marttunen, M.J., H.M. Aro, M.M. Henriksson and J.K. Lonngvist, 2007. Antisocial behaviour in adolescent suicide. Acta Psychiatrica Scandinavica, 89: 167-173.

Miller, S.J., S. Dinitez and J.P. Conrad, 1982. Careers of the violent. Lexington Books, Lexington, MA.

Nwankwo, B.O., 2004. Economics of Health Care Delivery. 1st Edn., Colon Concepts Ltd., Owerri, USA., ISBN: 978-37017-0-3, pp: 57-78.

Nwankwo, B.O., 2006a. Mental and Emotional Health. Megasoft Publishers, Owerri, ISBN: 978-36223-4-7.

Nwankwo, B.O., 2006b. Chemical Substances and Human Behav iour. Onii Publishers, Owerri, ISBN: 978- 38432$0-6$.

Nwankwo, B.O., O.C. Abanobi and A.N. Amadi, 2008. Antecedents to smoking behaviour among male adolescent students in South East region, Nigeria. Int. J. Trop. Med., 3: 60-65.

Ogidefa, I., 2008. Cultism in educational institutions in Nigeria. Education, (April 22). Retrieved. http://socyberty.com/education/cultism-in-educational-institutions-in-nigeria/.

Rigotti, N., J.E. Lee and H. Wechsler, 2000. US college students use of tobacco products: Results of a national survey. JAMA, 284: 699-705.

Roberts, A., 1981. Mental health history timeline. Middlesex University. Retrieved on 28/3/2010@8pm. http://studymore.org.uk/mhhtim.htm.

Robins, L., 1986. Changes in Conduct Over Time. In: Risk in Intellectual and Psychosocial Development, Faran, D.C. and J.D. McKinney (Eds.). Academic Press, Orlando, FL, pp:227-259.

Rutter, M. and H. Giller, 1983. Juvenile Delinquency: Trends and Perspectives. Middlesex, Pengiun, UK.

Zajonc, R.B. and D.N. McIntosh, 1992. Emotions research: Some promising questions, some questionable promises. Psychol. Sci., 3: 70-74. 